\title{
CONTENT
}

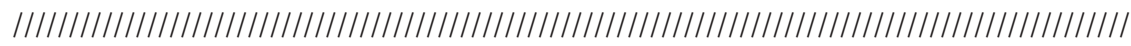

1. Prologue. Why Rain?

9

2. Graphemes. Cave and Clay

17

3. Towards a Hermeneutic of Cave Spaces

37

4. Rain-Therapies and Aby Warburg

55

5. From Zettelkast 6 to Mithras

73

6. Environment and the Participation Model

91

7. Old and New Abstractions

107

8. Bilderatlas. Rain-Saints and Folk-Art - By Julia van Rosmalen

129

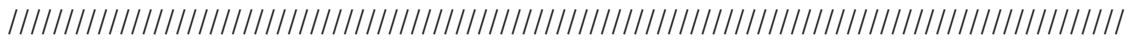




\section{Drawing \\ 139}

10. Canvassing

155

11. Oculi. Danaë and the Uncanny Space

173

12. One cannot escape the wetscape. Rain and Woody Allen

197

13. Epilogue. A life of the 'it' in it rains

207

Bibliography

213

Index nominum

227

Image Credits

233

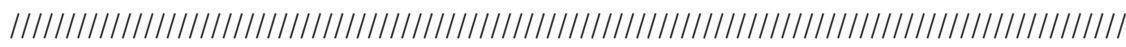


